\title{
The degree of early inbreeding depression determines the selfing rate at the seed stage: model and results from Pinus sylvestris (Scots pine)
}

\author{
KATRI KÄRKKÄINEN* \& OUTI SAVOLAINEN \\ Department of Genetics, University of Oulu, SF-90570 Oulu, Finland
}

\begin{abstract}
Early inbreeding depression, i.e. embryonic recessive lethals, eliminates a large proportion of selfed progeny during embryo development. A model of early inbreeding depression suggested that in most conifers the variation between genotypes in the number of lethals rather than the variation in the actual rate of self-fertilization accounts for the variation between selfing rates at the seed stage. Polyembryony, the formation of several embryos per ovule in conifers, diminished the fitness cost of embryonic lethals and allowed embryo competition. We studied variation in the outcrossing rate at the seed stage in an experimental population of Scots pine. Despite extensive variation, pollen production of the trees, which is expected to predict the probability of self-fertilization, did not account for the low selfing rate variation at the seed stage. The genotypes having lowest numbers of embryonic lethals had the highest selfing rates at the seed stage. Early inbreeding depression maintains a very low selfing rate at the seed stage and masks the correlation between the rate of selffertilization and the selfing rate at the seed stage. This is typical of most conifers and can also be common among perennial angiosperm species.
\end{abstract}

Keywords: conifers, embryonic lethals, inbreeding depression, P. sylvestris, polyembryony, selffertilization.

\section{Introduction}

The degree of outcrossing is not necessarily a fixed character within species but can vary between individuals and populations (Barrett \& Eckert, 1990). The observed variation in the outcrossing rate can be caused partly by genetic variation, e.g. spatial and temporal isolation of male and female functions (Erickson \& Adams, 1990; Holtsford \& Ellstrand, 1992) and partly by environmental factors, e.g. the density and family structure of populations or movements of pollinators (Ellstrand et al., 1978; Epperson \& Clegg, 1987). Correlations between estimated selfing rates and factors that are expected to influence the rate of self-fertilization are difficult to demonstrate (Neale \& Adams, 1985; Denti \& Schoen, 1988). The difficulty can be caused by selection that acts between the time when self-fertilization occurs and the time when the selfing rate is estimated. This selection, early inbreeding depression, is caused by embryonic lethals and is typical of many outcrossing species (Charlesworth \&

\footnotetext{
*Correspondence.
}

Charlesworth, 1987). Its existence has been known for a long time in conifers (Sorensen, 1969) but its influence on the estimation of mating system variation has not been completely realized (but see Charlesworth \& Charlesworth, 1987).

Scots pine, like most conifers, is a monoecious, windpollinated and predominantly outcrossing species (Muona, 1989); however, some between-population and -individual variation in the selfing rate has been observed (Koski \& Muona, 1986; Kärkkäinen \& Muona, 1991). The production of male and female flowers in the same individual and the absence of a prezygotic self-incompatibility system make considerable self-fertilization possible. Temporal and spatial isolation of male and female function can prevent selfing in conifers to some degree but not completely (Chung, 1981; Omi \& Adams, 1986; Erickson \& Adams, 1990). If the concentration of the tree's own pollen around a crown is high, the probability of selfpollination is also expected to be high. Thus, selfing should be more common in sparse than dense populations. In some studies, sparse conifer populations have had higher selfing rates (Farris \& Mitton, 1984; 
Knowles et al., 1987) but in many others - despite large differences in densities - no such trend has been found (Neale \& Adams, 1985; Furnier \& Adams, 1986). Similarly, individuals with high pollen production can be expected to have lower outcrossing rates than trees that produce less pollen. The relationships, however, between pollen production of individuals and their estimated outcrossing rates have also been rather weak (Shea, 1987; Denti \& Schoen, 1988).

In conifers, the mating system is usually estimated from germinated seeds. A large proportion of selfed zygotes, however, are killed by recessive lethal genes before the seed stage during embryo development (Namkoong \& Bishir, 1987). Koski (1971) found that on controlled selfing of Scots pine, on average, 85 per cent of the ovules produce no live seed which corresponds to 9.4 recessive lethal equivalents per diploid genome. The degree of inbreeding depression is not constant but varies between genotypes (Koski, 1971, 1973) and there are some suggestions that it may also vary between conifer populations (Namkoong \& Bishir, 1987; K. Kärkkäinen et al., unpublished data). The varying degree of early inbreeding depression can mask the correlation between factors that influence the rate of self-fertilization and the selfing rate at the seed stage.

In this paper we use a model which contrasts the selfing rate at the time of fertilization with the selfing rate at the seed stage, when the degree of early inbreeding depression was allowed to vary. The values of parameters describe the range of mating systems of conifers and those angiosperm species which express early inbreeding depression. We also present empirical results of selfing rate variation at the seed stage in Scots pine and two factors which influence the selfing rate: pollen production and the degree of early inbreeding depression.

\section{Materials and methods}

\section{Model: rate of self-fertilization vs. selfing rate of the seeds}

We studied how variation in the rate of self-fertilization and degree of inbreeding depression influence the selfing rate of seeds. The model, modified from Lindgren (1975), is described in Savolainen et al. (1992) where it was used to estimate the numbers of embryonic lethals. The rate of self-fertilization ranged within the limits of most conifers (Sarvas, 1962; Sorensen, 1982) from 0.25 to 0.75 . In the model, the parental trees were assumed to be heterozygous at $n$ loci for embryonic lethals. The number of loci varied between 0 and 20, corresponding to the range in conifers (Koski, 1971; Namkoong \& Bishir, 1987). Embryonic lethals were assumed to be fully recessive, independently operating lethal genes. If, following selffertilization, an embryo were homozygous for a lethal gene it would die. If an ovule were not to have a live embryo, the endosperm will also degenerate and the seed will be empty (Sarvas, 1962). Unpollinated ovules can also cause empty seeds in angiosperms and some conifer species (Sedgley \& Griffin, 1989). Here we assume that lack of pollination does not cause empty seeds. This assumption is true for pines (Sarvas, 1962).

In many conifer species, the ovules contain several archegonia that can be pollinated by different pollen grains. This condition is termed polyembryony. During seed development, one embryo will outcompete the others (Sarvas, 1962). Thus, abortion of one embryo will not automatically lead to the abortion of the seed. The number of embryos in an ovule, $k$, is one or two in our models. In Scots pine, on the average 1.7 archegonia per ovule are fertilized (Sarvas, 1962). We assume that the probabilities of genetic death of the embryos in the same ovule are not independent because all the egg nuclei in the ovule share the same haploid genotype.

Seed abortions are assumed to be either completely the result of embryonic lethals or, in some cases, an environmental effect. In our model, the probability of environmental deaths was given a value of either 0 or 0.3 . In an experiment where possibilities of genetic death were excluded, on the average 9 per cent of the seeds were empty in Scots pine (Sarvas, 1962). If two embryos per ovule were fertilized, 30 per cent environmental abortions of embryos would cause 9 per cent empty seeds.

If two embryos within an ovule were to survive the outcome of the competition between them can be assumed to be either random (fitness of outcrossed and selfed embryos are both 1.0) or the fitness of selfed embryos in competition can be less than that of outcrossed ones (here 0 ). The proportion of ovule abortions is described as the frequency of empty seeds. The outcrossing rate at the seed stage is the frequency of selfed seed among sound (non-aborted) seed.

\section{Selfing rate variation within a Scots pine population}

Our experimental study population was the Viitaselkä seed orchard in southern Finland $\left(62^{\circ} 15^{\prime} \mathrm{N}\right.$, $27^{\circ} 35^{\prime} \mathrm{E}$ ). It includes 25 tree genotypes (clones) which originate from a restricted geographical area between latitudes $61^{\circ} 05^{\prime}$ and $61^{\circ} 50^{\prime}$. Each clone was represented by approximately 20 trees (grafts; see Muona \& Harju, 1989, for details). 
In 1985 we estimated pollen production from individual trees using the method described in Muona \& Harju (1989). The pollen production estimate is presented as grams of pollen per tree.

The production of mature cones takes 1 year in Scots pine. In 1986, mature cones which were pollinated in 1985 were collected separately by tree from the same trees used to estimate pollen production. The genotypes of the embryo and the megagametophyte were determined at seven enzyme loci (e.g. Muona $e t$ al., 1988): glutamate dehydrogenase $(G d h)$, glutamateoxaloacetate transaminase (Got-2), fluorescent esterase (Fest), leucine amino peptidase (Lap-2), malate dehydrogenase $(M d h-3)$, 6-phosphogluconate dehydrogenase (6-Pgd-2) and shikimate dehydrogenase $(S h d h-1)$. Outcrossing rates were estimated using a mixed mating model adapted for conifer data (Ritland \& El-Kassaby, 1985). We analysed the outcrossing rate from 24 trees representing 18 clones. The number of seeds assayed varied from 32 to 134 per tree. For six clones, we also studied clonal outcrossing rates by pooling analysed seeds from two trees per clone. The sample sizes were all over 100 per clone for these estimates.

In the experiment, a small proportion of detected selfing comes from other trees of the same clone so that the rate of within-tree selfing is slightly overestimated. The grafts of the same clones were never neighbours in the seed orchard. Based on flowering variation, the probability of random mating between trees of the same clone should be less than 5 per cent if all matings occur within the orchard (Muona \& Harju, 1989), and because 30 per cent of the fertilizing pollen grains came from outside the orchard (Harju \& Muona, 1989) the probability of self-fertilization between grafts was even lower. There was no mating between relatives because the clones in this orchard originated from different stands.

The number of embryonic lethal equivalents was estimated from the proportion of empty seeds in experimental self-pollinations. Details on methods and results of selfing of some of the clones of the Viitaselkä seed orchard have been published by Koski (1971) and Koski \& Muona (1986).

\section{Results}

\section{Model predictions}

The model suggests that the level of early-acting inbreeding depression had a pronounced effect on the level of selfing among the sound seeds. Low numbers of embryonic lethals maintained a high outcrossing rate at the seed stage despite 25 per cent self-fertilization (Fig. 1a). The relationship between the number of embryonic lethals and the outcrossing rate at the seed stage is non-linear. More variation could be seen in the outcrossing rates of the seeds when self-fertilization became more common. The outcrossing rate decreased, however, only if the number of embryonic lethals was quite low. Eight embryonic lethals reduced the proportion of selfs from 50 per cent at fertilization to less than 10 per cent among the seeds (Fig. 1b).

Polyembryony as such, without selection favouring outcrosses, did not increase the level of outcrossing (Fig. 1; Lindgren, 1975). The existence of polyembry-
Fig. 1 Expected outcrossing rates and empty seed frequencies in different rates of self-fertilization: (a) 25 per cent self-fertilization, (b) 50 per cent selffertilization, (c) 75 per cent self-fertilization). $\mathrm{k}=$ number of embryos per ovule; $\mathrm{k}=1(-), \mathrm{k}=2(---)$. Outcrossing rate: if two embryos survive after environmental and genetic deaths, either outcrossed embryos win, $w(s)=0$ (-..--) or the outcome of competition is random, $w(s)=1(---)$. Frequency of empty seeds: $d=$ frequency of environmental deaths; $\mathrm{k}=1, \mathrm{~d}=0$ (- $(-)$, $\mathrm{k}=1, \mathrm{~d}=0.3(\longrightarrow), \mathrm{k}=2, \mathrm{~d}=0$ $(---), \mathrm{k}=2, \mathrm{~d}=0.3(---*---)$.
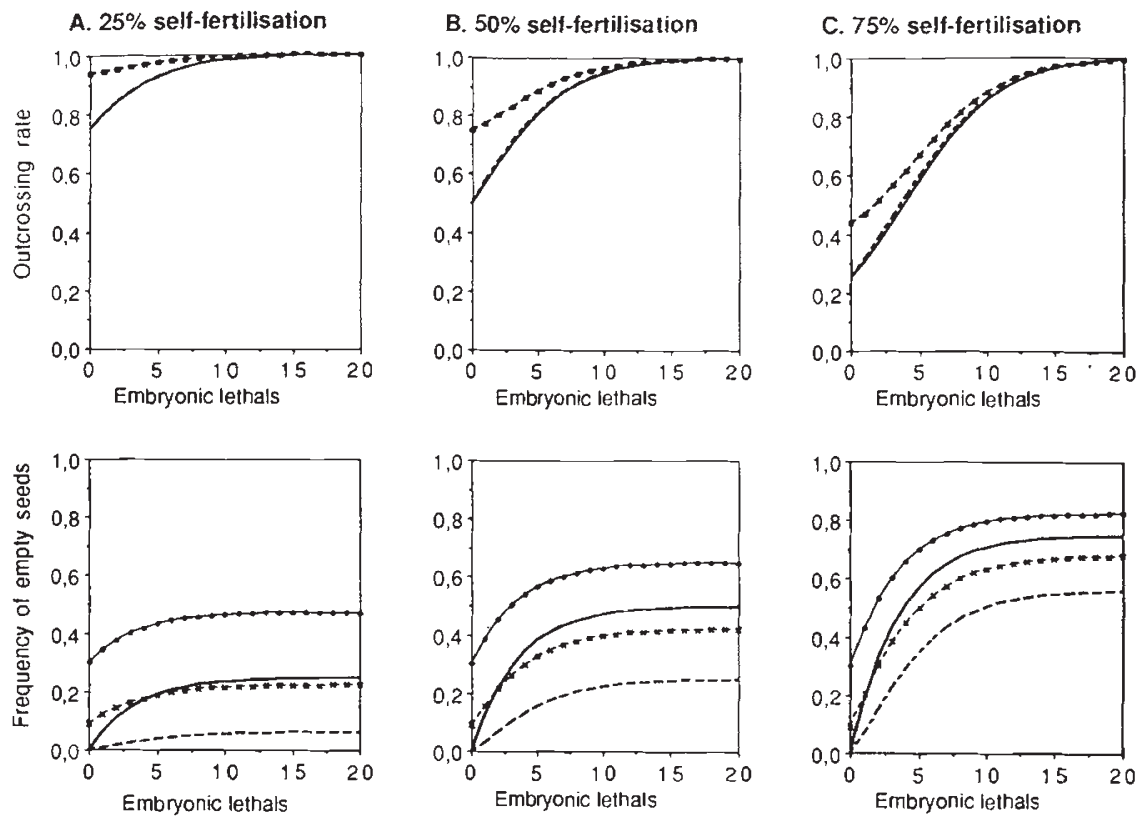
ony, however, means that embryo competition is possible. If the outcrossed embryos were assumed to outcompete selfed ones, the realized outcrossing rate is clearly higher than if the outcome were random (Fig. 1; $w(s)=1$ or 0$)$. The effect is most pronounced where this kind of competition is most probable (the proportion of outcrossed pollen is 0.5 ). If self-fertilization is rare and the selfed embryos lose in the competition with outcrossed ones, nearly complete outcrossing would be predicted (Fig. 1a).

Self-fertilization causes abortions of embryos, which results in empty seeds, but polyembryony diminishes effectively the rate of reproductive failure. When 25 per cent of the embryos are self-fertilized and an individual carries 10 embryonic lethals, 24 per cent of the seeds will be aborted if ovules have only one embryo. If two embryos per ovule are fertilized, only 5 per cent of the seeds will be empty because of embryonic lethals (Fig. 1a). Deaths from environmental causes raised the total abortion rates but did not diminish the influence of polyembryony (Fig. 1a-c). Polyembryony failed to rescue the ovules and more empty seeds were formed (Fig. 1b-c) when self-fertilization was very common.

\section{Mating system variation in the Viitaselkä seed orchard}

Pollen production of the trees. Pollen production differed among the study trees in the Viitaselkä seed orchard from $54 \mathrm{~g}$ to $1014 \mathrm{~g}$ (C.V. $=0.53$; Table 1). The total pollen production of these clones ranged from $1620 \mathrm{~g}$ to $23,460 \mathrm{~g}$ (data not shown). There were statistically significant differences between clones in pollen production in the seed orchard $(F=2.60$, $P<0.0007)$ and 51 per cent of the total variation was explained by the clones.

Flowering in the orchard was simultaneous and pollen shedding in the orchard lasted less than a week (O. Savolainen et al., unpublished data). Unfortunately we do not have data about female receptivity. Complete avoidance of selfing by different timing of male and female receptivity seemed to be impossible as pollen shedding occurred within a very short period.

Selfing rate at the seed stage. We detected low selfing at the seed stage in the Viitaselkä seed orchard, the outcrossing rate of the population was 0.976 (s.d. $=0.009$, $N=1846$ seeds). The mating system of the trees varied from complete outcrossing to 12 per cent selfing (Table 1). The variation in selfing rates between trees of the same clones was small (Table 1).

The pollen production of a tree is expected to influence its rate of self-fertilization because timing of
Table 1 Total pollen production, multilocus outcrossing rates $\left(t_{m}\right)$ and their standard errors and numbers of seeds assayed in the experimental population of Scots pine. Grafts with the same number but different letter (e.g. 719 and 719D) are of different genotype

\begin{tabular}{|c|c|c|c|c|}
\hline Clone & $\begin{array}{l}\text { Pollen } \\
\text { production } \\
\text { (g) }\end{array}$ & $t_{m}$ & S.E. & $\mathrm{N}$ \\
\hline$E 2$ & 551 & 0.95 & 0.05 & 134 \\
\hline$E 88 X$ & 650 & 0.99 & 0.04 & 89 \\
\hline$E 88 Y$ & 657 & 0.99 & 0.04 & 55 \\
\hline E165 & 100 & 0.98 & 0.04 & 113 \\
\hline E165 & 380 & 1.23 & 0.16 & 32 \\
\hline$E 470 D$ & 704 & 0.98 & 0.04 & 106 \\
\hline$E 470 D$ & 1014 & 1.08 & 0.11 & 35 \\
\hline E707 & 733 & 0.88 & 0.03 & 121 \\
\hline$E 708$ & 378 & 0.98 & 0.04 & 70 \\
\hline$E 708$ & 241 & 0.95 & 0.02 & 41 \\
\hline E709 & 429 & 0.95 & 0.02 & 100 \\
\hline$E 710$ & 54 & 1.00 & 0.06 & 34 \\
\hline$E 718$ & 250 & 0.95 & 0.07 & 63 \\
\hline$E 718$ & 237 & 1.06 & 0.09 & 53 \\
\hline E719 & 554 & 0.93 & 0.03 & 90 \\
\hline$E 719 D$ & 141 & 0.93 & 0.03 & 46 \\
\hline$E 719 D$ & 199 & 0.93 & 0.03 & 41 \\
\hline E720 & 988 & 0.90 & 0.09 & 106 \\
\hline E722 & 539 & 1.04 & 0.07 & 86 \\
\hline$E 722$ & 546 & 1.09 & 0.08 & 77 \\
\hline$E 726$ & 519 & 1.05 & 0.09 & 33 \\
\hline$E 728$ & 507 & 1.01 & 0.08 & 78 \\
\hline$E 728 X$ & 676 & 0.99 & 0.06 & 61 \\
\hline$E 736$ & 633 & 0.88 & 0.06 & 54 \\
\hline
\end{tabular}

pollen shedding and female receptivity overlap. Pollen production, however, did not predict the selfing rate at the seed stage of the trees, linear regression was not significant and explained only 0.002 per cent of the variation (Fig. 2a). The regression between the clonal selfing rate and the total amount of pollen a clone produced was also very weak and non-significant. Small flowering time differences of the trees did not explain variation in the selfing rate (comparison of early-, mid- or late-flowering trees, $F=2.01, P=0.17$ ).

The degree of early inbreeding depression was studied with controlled self-pollinations from five genotypes in the Viitaselkä seed orchard. The estimated numbers of embryonic lethals of different trees varied from seven to over 20 (Koski, 1971; Koski \& Muona, 1986). The relationship between numbers of embryonic lethals and level of outcrossing of different clones is shown in Fig. 2(b). The clones with least lethals had the lowest outcrossing rates. The outcrossing rate variation at the seed stage was fairly 
Fig. 2 Influence of different factors on the selfing rate at the seed stage in an experimental population of Scots pine. (a) Outcrossing rate $(t)$ and pollen production of individual trees. (b) Outcrossing rate $(t)$ and the level of early inbreeding depression (number of embryonic lethals) of clones. The curve is based on the model, given 25 per cent of self-fertilization, either one or two embryos per ovule and random survival of embryos in competition.
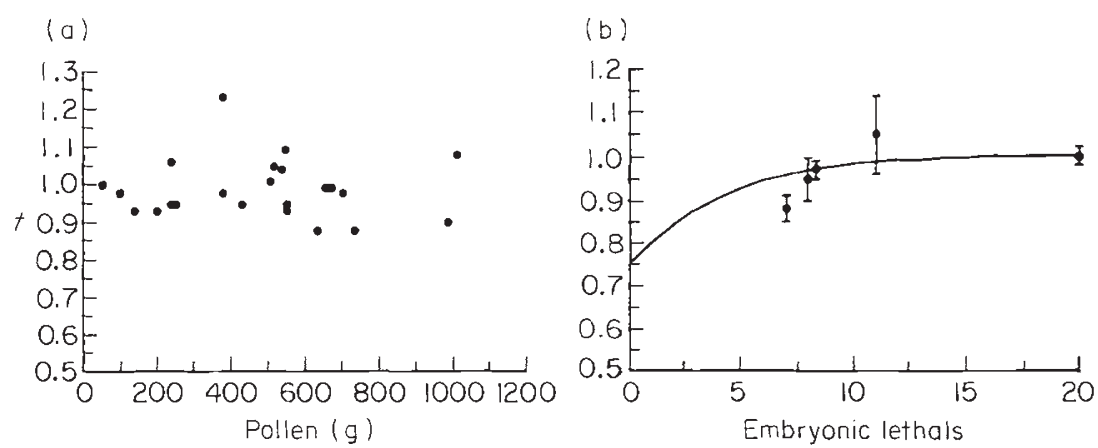

similar to what would be expected if 25 per cent of the embryos of these trees were self-fertilized (curve in Fig. $2 b)$.

\section{Discussion}

\section{Outcrossing rate of the seeds depends on the early inbreeding depression}

Inbreeding depression is severe in most conifers. It acts in all life stages but it is most pronounced during the late development of embryos (Sarvas, 1962; Koski, 1973). The average numbers of embryonic lethals per tree are 9-10 in most conifers (Namkoong \& Bishir, 1987). Some of these values are overestimates but the average numbers are still relatively high and the variation between trees is substantial (Bishir \& Namkoong, 1987; Savolainen et al., 1992). The severe early inbreeding depression also suggests that the small variation in outcrossing rates that is found in conifers at the seed stage reflects much larger variation at the actual time of fertilization. That conifers are not completely outcrossing and that self-fertilization is rather common has evolutionary consequences because it markedly affects the equilibrium frequencies of embryonic lethals (Lande \& Schemske, 1985; Charlesworth et al., 1990).

The importance of early inbreeding depression in the mating system of conifers has been realized earlier. Lindgren (1975) and Sorensen (1982) modelled the relationship between self-pollination and proportion of selfed seeds. In Sorensen's (1982) model, early inbreeding depression was presented as relative selffertility that is constant within a species. He compared the mating system of two species: the self-infertile Douglas fir and the more self-fertile Noble fir. The results agree with ours: species with severe early inbreeding depression had little variation in the selfing rate at the seed stage whereas the proportion of selfed seeds in the relatively self-fertile species was more dependent on the rate of self-pollination. We argue that the same is true at the individual and population level. The estimates of numbers of embryonic lethals varied from three to 20 in Scots pine (Koski, 1971), between three and 28 in Douglas fir and from three to 14 in Lodgepole pine (see Mitchell-Olds \& Guries, 1986). This kind of variation in the degree of early inbreeding depression must influence the realized outcrossing rate of the seeds and mask the relationship between actual self-fertilization and the selfing rate of the seeds. The average number of lethals carried by trees can also vary among populations which could cause regional differences in the selfing rates at the seed stage. Namkoong \& Bishir (1987) noticed that the variances of embryonic lethal numbers were higher than expected when the trees were sampled over a wide geographic range. Estimates based on individuals from a small area had smaller variances. In Scots pine, there seems to be geographical variation in the number of embryonic lethals (K. Kärkkäinen et al., unpublished data).

The model showed that variation in factors that influence the rate of self-fertilization should affect the outcrossing rate at the seed stage only if the degree of early inbreeding depression is low. All the genotypes studied in our experimental population carried several embryonic lethals. Thus, the low variation in the selfing rate at the seed stage and the poor correlation between pollen production and outcrossing rate can be expected. In a white spruce population, where flowering variation was even more pronounced than in this study, pollen production could explain 63 per cent of the variation in selfing rate in polynomial regression (Denti \& Schoen, 1988); however, this relationship was mainly caused by two genotypes. Denti \& Schoen (1988) concluded that unexplained selfing variation was likely to be caused by variation in the numbers of embryonic lethals of different individuals. Spatial separation of male and female flowers or variation in flowering phenology should also influence the rate of self-fertilization. Omi \& Adams (1986) compared the level of selfing in different parts of Douglas fir trees. Only two clones (with a low number of embryonic 
lethals?) had higher selfing rates in the lower parts of the crown where female flowers are close to male flowers. The remaining clones had high outcrossing rates in all parts of the crown. Erickson \& Adams (1990) found more selfing in clones where male and female flowering overlapped than in clones with less overlap in flowering times. Flowering time could not explain all the selfing variation, the inherent selffertility' was also considered to play a significant role. Other factors than embryonic lethals can clearly influence the selfing rate but lethals set limits to the realized selfing rate variation of the seeds. Those other factors shape the mating system of Picea omorika, which has very few embryonic lethals, but is still highly outcrossing (Kuittinen \& Savolainen, 1992).

\section{Genetic load is lighter to bear with polyembryony}

Polyembryony diminishes the cost of embryonic lethals. Some selfed embryos can be aborted without decreasing the total fecundity of the individual. With a low selfing rate and with efficient pollination (many embryos per ovule are fertilized), the loss of total fecundity is very low but when selfing is more abundant many seeds will be aborted and reproductive success decreases (Fig. 1).

Polyembryony also makes embryo competition possible. Selfed embryos may have a lower competitive ability than outbred embryos and thus polyembryony may favour outcrossing. Polyembryony also allows selection between outcrossed embryos. Unequal contributions of pollen parents have been detected in many polymix crosses (Moran \& Griffin, 1985; Schoen \& Cheliak, 1987; El-Kassaby \& Ritland, 1992). This could result from competition of pollen gametes which is described in some angiosperms (Snow \& Spira, 1991) but, as Nakamura \& Wheeler (1992) have shown, in conifers it is more likely to be from competition of embryos in polyembryony. This system allows natural selection without a concomitant reduction in seed set.

It is not only conifers that suffer from embryonic lethals. Recent studies have documented high average numbers of embryonic lethals in perennial angiosperm species. For example, 9.6 embryonic lethals were estimated in Vaccinium corymbosum (Krebs \& Hancock, 1991) and on the average 9.7 in 53 Australian Stylidium species (Burbidge \& James, 1991). In these species, the mating system can be expected to be similar to conifers: embryonic lethals keep the outcrossing rate of seeds high but self-fertilization can still be fairly common. Selfing without polyembryony causes a substantial rate of ovule abortion. Thus, early inbreeding depression can explain part of the low female reproductive success commonly found in outcrossing angiosperm species (Wiens et al., 1987; Charlesworth, 1989).

\section{Acknowledgements}

Veikko Koski provided the estimates of embryonic lethals of the clones. Anni Harju and Mari Rusanen fearlessly helped us in climbing trees for male strobilus counting. We also thank Anni Harju for helping with the electrophoresis and Susan Kalisz for comments on the manuscript. The National Board of Forestry provided the seeds. Our research was funded by the National Research Council for Agriculture and Forestry.

\section{References}

BARRETT, S. H. AND ECKERT, C. G. 1990. Variation and evolution of mating systems in seed plants. In: Kawano, S. (ed.) Biological Approaches and Evolutionary Trends in Plants, Academic Press, London, pp. 230-254.

BISHIR, J. AND NAMKOONG, G. 1987. Unsound seeds in conifers: estimation of lethal alleles and of magnitudes of effects associated with the maternal parent. Silvae Genetica, 36, 180-185.

BuRbidGe, A. H. AND JAMES, s. H. 1991. Postzygotic seed abortion in the genetic system of Stylidium (Angiospermae: Stylidaceae). J. Hered., 82, 319-328.

CHARLESWORTH, D. 1989. Why do plants produce so many more ovules than seeds? Nature, 338, 21-22.

CHARLESWORTH, D. AND CHARLESWORTH, B. 1987. Inbreeding depression and its evolutionary consequences. Ann. Rev. Ecol. Syst., 18, 237-268.

CHARLESWORTH, D., MORGAN, M. T. AND CHARLESWORTH, B. 1990. Inbreeding depression, genetic load and the evolution of outcrossing rates in a multilocus system with no linkage. Evolution, 44, 1469-1489.

CHUNG, M.-s. 1981. Flowering characteristics of Pinus sylvestris $\mathrm{L}$. with special emphasis on the reproductive adaptation to local temperature factor. Acta Forestalia Fennica, 169, 1-68.

DENTI, D. AND SCHOEN, D. J. 1988. Self-fertilization rates in white spruce: effect of pollen and seed production. $J$. Hered., 79, 284--288.

EL-KASSABY, Y. A. AND RITLAND, K. 1992. Frequency-dependent male reproductive success in a polycross of Douglas fir. Theor. Appl. Genet., 83, 752-758.

ELLSTRAND, N. C., TORRES, A. M. AND LEVIN, D. A. 1978. Density and the rate of apparent outcrossing in Helianthus (Asteraceae). Syst. Bot., 3, 403-407.

EPPERSON, B. K. AND CLEGG, M. T. 1987. Frequency-dependent variation for outcrossing rate among flower-color morphs of Ipomoea purpurea. Evolution, 41, 1302-1311.

ERICKSON, v. J. AND ADAMS, w. T. 1990. Mating system variation among individual ramets in a Douglas-fir seed orchard. Can.J. For. Res., 20, 1672-1675. 
FARRIS, M. A. AND MITTON, J. B. 1984. Population density, outcrossing rate and heterozygote superiority in ponderosa pine. Evolution, 38, 1151-1154.

FURNIER, G. R. AND ADAMS, w. T. 1986. Mating system in natural populations of Jeffrey pine. Am. J. Bot., 73, 1002-1008.

HARJU, A. AND MUONA, o. 1989. Background pollination in Pinus sylvestris seed orchards. Scand. J. For. Res., 4, 513-520.

HOLTSFORD, T. P. AND ELLSTRAND, N. C. 1992. Genetic and environmental variation in floral traits affecting outcrossing rate in Clarkia tembloriensis (Onagraceae). Evolution, 46, 216-225.

KÄRKKÄlNEN, K. AND MUONA, O. 1991. Reproduction of Pinus sylvestris at the northern timber line. In: Fineschi, S., Malvolti, M. E., Cannata, F. and Hattemer, H. H. (eds), Biochemical Markers in the Population Genetics of Forest Trees, SPB Academic Publishers, The Hague, p. 247.

KNOWLES, P., FURNIER, G. R., ALEKSIUK, M. A. AND PERRY, D. J. 1987. Significant levels of self-fertilization in natural populations of tamarack. Can. J. Bot., 65, 1087-1091.

Koski, v. 1971. Embryonic lethals of Picea abies and Pinus sylvestris. Commun. Inst. For. Fenn., 75, 3, 1-30.

Kosk1, v. 1973. On self-pollination, genetic load and subsequent inbreeding in some conifers. Commun. Inst. For. Fenn., 78, 10, 1-42.

KOSK1, v. AND MUONA, o. 1986. Probability of inbreeding in relation to clonal differences in male flowering and embryonic lethals. Proceedings IUFRO Conference on Breeding Theory, Progeny Testing and Seed Orchards, Williamsburgh, Virginia, 13-17 October, 1986, pp. 391-400.

KREBS, S. L. AND HANCOCK, J. F. 1991. Embryonic genetic load in the highbush blueberry, Vaccinium corymbosum (Ericaceae). Am. J. Bot., 78, 1427-1437.

KUITTINEN, H. AND SAVOlainen, o. 1992. Picea omorika is a fully self-fertile but outcrossing conifer. Heredity, 68, 183-187.

LANDE, R. AND SCHEMSKE, D. W. 1985. The evolution of selffertilization and inbreeding depression in plants. I. Genetic models. Evolution, 39, 24-40.

LINDGREN, D. 1975. The relationship between self-fertilization, empty seeds and seeds originating from selfing as a consequence of polyembryony. Studia Forestalia Suecica, 126, 1-24.

MITCHELl-OldS, T. AND GURIES, R. P. 1986. Genetic load and heterozygosity in the Pinaceae. Can. J. Genet. Cytol., 28, 942-946.

MORAN, G. F. AND GRIFFIN, A. R. 1985. Non-random contribution of pollen in polycrosses of Pinus radiata D. Don. Silvae Genet., 34, 4-5.

MUONA, o. 1989. Population genetics in tree improvement. In: Brown, A. H. D., Clegg, M. T., Kahler, A. L. and Weir, B. S. (eds), Plant Population Genetics, Breeding and Genetic Resources, Sinauer Sunderland, MA, pp. 282-298.
MUONA, O. AND HARJU, A. 1989. Effective population sizes, genetic variability and mating system in natural stands and seed orchards of Pinus sylvestris. Silvae Genetica, 38, 221-228.

MUONA, O., HARJU, A. AND KÄRKKÄINEN, K. 1988. Genetic comparison of natural and nursery grown seedlings of Pinus sylvestris. Scand. J. For. Res., 4, 37-46.

NAKAMURA, R. R. AND WHEEleR, N. C. 1992. Pollen competition and paternal success in Douglas-fir. Evolution, 46, $846-851$.

NAMKOONG, G. AND BISHIR, J. 1987. The frequency of lethal alleles in forest tree populations. Evolution, 41, 1123-1127.

NEALE, D. B. AND ADAMS, w. T. 1985. The mating system in natural and shelterwood stands of Douglas-fir. Theor. Appl. Genet., 71, 201-207.

OM1, S. K. AND ADAMS, w. T. 1986. Variation in seed set and proportions of outcrossed progeny with clones, crown position and top pruning in a Douglas-fir seed orchard. Can. J. For. Res., 16, 502-507.

RITLAND, K. AND EL-KASSABY, Y. A. 1985. The nature of inbreeding in a seed orchard of Douglas fir as shown by an efficient multilocus model. Theor. Appl. Genet., 71, 375-384.

SARVAS, R. 1962. Investigations on the flowering and seed crop of Pinus sylvestris. Commun. Inst. For. Fenn., 53, 4, $1-198$.

SAVOLAINEN, O., KÄRKKÄINEN, K. AND KUITTINEN, H. 1992. Estimating numbers of embryonic lethals in conifers. Heredity, 69, 308-314.

SCHOEN, D. J. AND CHELIAK, w. M. 1987. Genetics of the polycross. 2. Male fertility variation in Norway spruce, Picea abies (L.). Karst. Theor. Appl. Genet., 74, 554-559.

SEDGley, M. AND GRIFFin, A. R. 1989. Sexual Reproduction of Tree Crops, Academic Press, London.

SHEA, K. L. 1987. Effects of population structure and cone production on outcrossing rates in Engelmann spruce and subalpine fir. Evolution, 41, 124-136.

SNOW, A. A. AND SPIRA, T. P. 1991. Differential pollen tube growth rates and non-random fertilization in Hibiscus moscheutos (Malvaceae). Am. J. Bot., 78, 1419-1426.

SORENSEN, F. 1969. Embryonic genetic load in coastal Douglas fir, Pseudotsuga menziesii var. menziesii. Am. Nat., 103, 389-398.

SORENSEN, F. C. 1982. The roles of polyembryony and embryo viability in the genetic system of conifers. Evolution, 36, $725-733$

WIENS, D., CALVIN, C. L., WILSON, C. A., DAVERN, C. I., FRANK, D. AND SEAVEY, S. R. 1987. Reproductive success, spontaneous embryo abortion, and genetic load in flowering plants. Oecologia, 71, 501-509. 